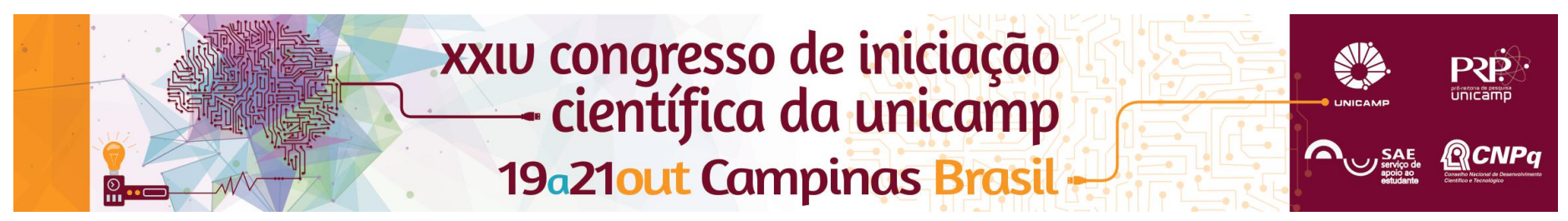

\title{
Finite Element Modeling of Cold-Formed Steel Members
}

\section{Victor Stangherlin Gomes*, Luiz Carlos Marcos Vieira Jr.}

\begin{abstract}
The study herein presented aims to better understand the behavior and resistance of Cold-Formed Steel Members based on a parametric Finite Element (FE) analysis. The study leads to an optimal performance of cold-formed steel member when submitted to a certain loading condition.
\end{abstract}

\section{Key words:}

Finite Elements, Cold-Formed Steel, Stability

\section{Introduction}

Cold-Formed Steel (CFS) members are obtained by rolling at low temperatures to achieve a desired shape, allowing higher strength and stiffness. If compared to other materials such as timber or concrete, CFS is lighter, faster to erect and install, and has uniform quality. Therefore, the use of Cold-Formed Steel members in construction can be very cost-effective. The main purpose of this research was to introduce the student to the academic world while learning a new set of tools and skills through a parametric study of finite element models.

\section{Results and Discussion}

At a first stage, FE models were compared to compression experiments carried out at LABMEM (Laboratório Modelagem de Estruturas e Monitoração) - FEC Unicamp of a CFS member with stiffeners. Based on the models previously developed, a clip CFS angle was studied in order to optimize the cross-section for maximum shear strength; the shear strength is parameterized per unit of weight $(\mathrm{Vn} / \mathrm{W})$ while still maintaining its fabrication feasibility.

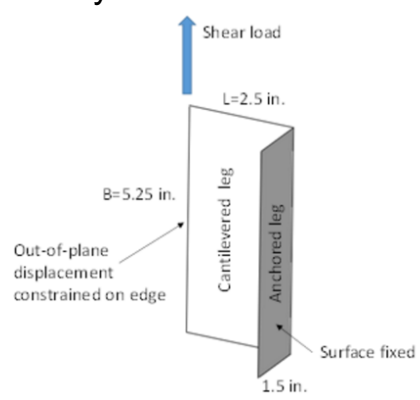

The parametric analysis leads to a simple, yet efficient design while slight changes are made to its geometry in which stiffeners are added where the shear strength is maximized.

Figure 1. Clip Angle

The parametric analysis consisted of a series of trial and error tests on the basic clip angle in Figure 1. The analysis varied the size, shape, and orientation of the stiffeners.

For example, given a triangular stiffener parallel to the shear load the optimization followed the steps below:

-Find the best position relative to the anchored leg for the stiffener;

-Change the shape of the stiffeners (triangular, squared and semicircular);

-Change the size of the stiffener.

Triangular stiffeners, however, did not lead to a satisfactory strength, thus, the addition of stiffeners perpendicular to the shear load were studied.
Chart 1. Final design $(\mathrm{Vn} / \mathrm{W})$

\begin{tabular}{|c|cccc|}
\hline \multicolumn{5}{|c|}{ Varying relative distance of center stiffeners } \\
\hline & N36 & N39 & N38 & N40 \\
\hline Abaqus Eigenvalue & 8,786 & 9,0214 & 9,2032 & 9,04 \\
Dist from Anchored Leg & 1,3 & 1,325 & 1,35 & 1,4 \\
Vn/W & 5265,4528 & 5321,435744 & 5328,6177 & 5326,4107 \\
\hline & & & & \\
\hline & & & & \\
\hline
\end{tabular}

Figure 2. Buckled shape of model N38

When comparing the basic clip CFS angle depicted in Figure 1 to the clip CFS angle depicted in Figure 2, a $30 \%$ increase in shear strength per unit of weight was achieved.

\section{Conclusions}

The study conducted showed the importance of computer simulation in order to find the best configuration of an element by exploiting its mechanical and geometrical properties, thus, making the use of CFS very advantageous and cost-effective. The study also lead to important findings of great interest to industries that are looking for optimizing the strength of CFS members manufactured to resist shear loading.

\section{Acknowledgement}

The authors would like to thank the National Counsel of Technological and Scientific Development (CNPq) for funding this research. Any opinions, findings, and conclusions or recommendations expressed in this material are those of the authors only and do not necessarily reflect the views of the sponsors.

${ }^{1}$ Abaqus v6.14 software documentation, Dassault Systèmes Simulia Corp., Providence, RI, USA, 2014.

${ }^{2}$ Carvalho, Paulo Roberto Marcondes de. Curso Básico De Perfis De Aço Formados A Frio. 2nd ed. Porto Alegre: N.p., 2006.

${ }^{3}$ Yu, Wei-wen, and Roger A LaBoube. Cold-Formed Steel Design. Hoboken, N.J.: Wiley, 2010 